\title{
Parasitism of Toxocara canis Larvae in Japanese Quails by Inoculation of the Ascarid Eggs
}

\author{
Satoru NAKAMURA, Tomoko SOTOYAMA, Shunya HAYASAKA, Yasuhiko KAMEYAMA, Soichi \\ MARUYAMA, and Yasuji KATSUBE
}

Laboratory of Veterinary Public Health, College of Agriculture and Veterinary Medicine, Nihon University, 1866 Kameino, Fujisawa, Kanagawa 252, Japan

(Received 22 April 1991/Accepted 27 June 1991)

\begin{abstract}
The distribution of $T$. canis larvae and pathological changes caused by them were studied in Japanese quails orally inoculated with 1,500, 4,000 or 15,000 embryonated eggs. Larvae were distributed mainly in the liver and, to lesser extent, in the muscles, brain, eyes and other organs. The number of larvae varied from 7 to 3,346, and from 1 to 288 in the liver and muscles (breast and legs), respectively. A small number of larvae were also recovered from the heart, gizzard, brain and eyes. In the groups of quails inoculated with 4,000 or 15,000 eggs, small white foci were observed on the surface of the liver 6 or $12 \mathrm{hr}$ after inoculation. Histopathological examinations revealed necrotic lesions, leukocytic infiltration, granuloma and nodular lesions. The pathological changes became more serious with the large size of inoculum and days after inoculation.--KEY wORDS: experimental infection, Japanese quail, larva migrans, Toxocara canis.
\end{abstract}

J. Vet. Med.Sci. 53(5): 865-872, 1991

Toxocara canis is a common nematode parasite in the small intestine of dogs, especially puppies, which frequently contaminate play-grounds for children, parks and roads with their feces containing ascarid eggs.

When embryonated ascarid eggs are ingested by indefinite hosts including man, somatic migration, so-called visceral larva migrans (VLM), may occur. It has been shown that various animals and birds serve as paratenic hosts for the ascarid $[3,6]$.

Many human VLM cases have been reported in many countries $[4,6,7]$ since the disease was propounded by Beaver [1]. In the majority of cases, VLM occurs in children by accidental ingestion of embryonated ascarid eggs in soil, sand, dirt and others contaminated with infected dog feces.

On the other hand, ingestion of raw or insufficiently cooked meat of paratenic hosts has been suggested to be another possible infection route of VLM. In some restaurants and/or home dishes in Japan, raw meat, liver, gizzard and heart of chicken, so-called "Zidori", are traditionally served. Meat and viscera of pheasants and/or Japanese quails are also consumed raw in some home cooking. However, little is known in Japan about the prevalence of Toxocara infection in poultry.

The authors studied the experimental infection of Japanese quails with $T$. canis and the major pathological changes in them by the infection.

\section{MATERIALS AND METHODS}

Preparation of embryonated eggs of $T$. canis: Eggs were harvested from the uterus of adult female of Toxocara canis obtained from dogs. Embryonated eggs were prepared by a slightly modified method of Kondo's [8]: Eggs were incubated at $30^{\circ} \mathrm{C}$ for 21 days in $0.5 \%$ formalin solution until the larvae in eggs developed to the second stage. After incubation, the eggs were washed three times with saline by centrifugation at $1,500 \mathrm{rpm}$ for $5 \mathrm{~min}$, and the outer shell membranes were removed by treatment with $20 \% \mathrm{NaOCl}$. Unembryonated or degenerated eggs were removed by treatment with $50 \% \mathrm{NaOCl}$ and centrifugation at $1,500 \mathrm{rpm}$ for $5 \mathrm{~min}$. After washed with saline by centrifugation, deposited embryonated eggs were collected and stored in N/10 $\mathrm{H}_{2} \mathrm{SO}_{4}$ at $4^{\circ} \mathrm{C}$. Prior to inoculation, the eggs were washed three times with saline by centrifugation at $1,500 \mathrm{rpm}$ for $5 \mathrm{~min}$ and resuspended in saline (Fig. 1).

Inoculation into Japanese quails: In Trial-1, a total of 33 3-week-old female Japanese quails (Coturnix coturnix japonica) weighing from 28 to $41 \mathrm{~g}$ was used. Each of 27 birds was given into the crops 0.2 $\mathrm{m} l$ of the suspension containing 1,500 embryonated eggs, with a silicon coated metal catheter $1 \mathrm{~mm}$ in diameter and $70 \mathrm{~mm}$ in length. The other 6 birds were used as control.

In Trial-2, a total of 79 3-week-old male Japanese quails weighing from 22 to $35 \mathrm{~g}$ was used. The birds 


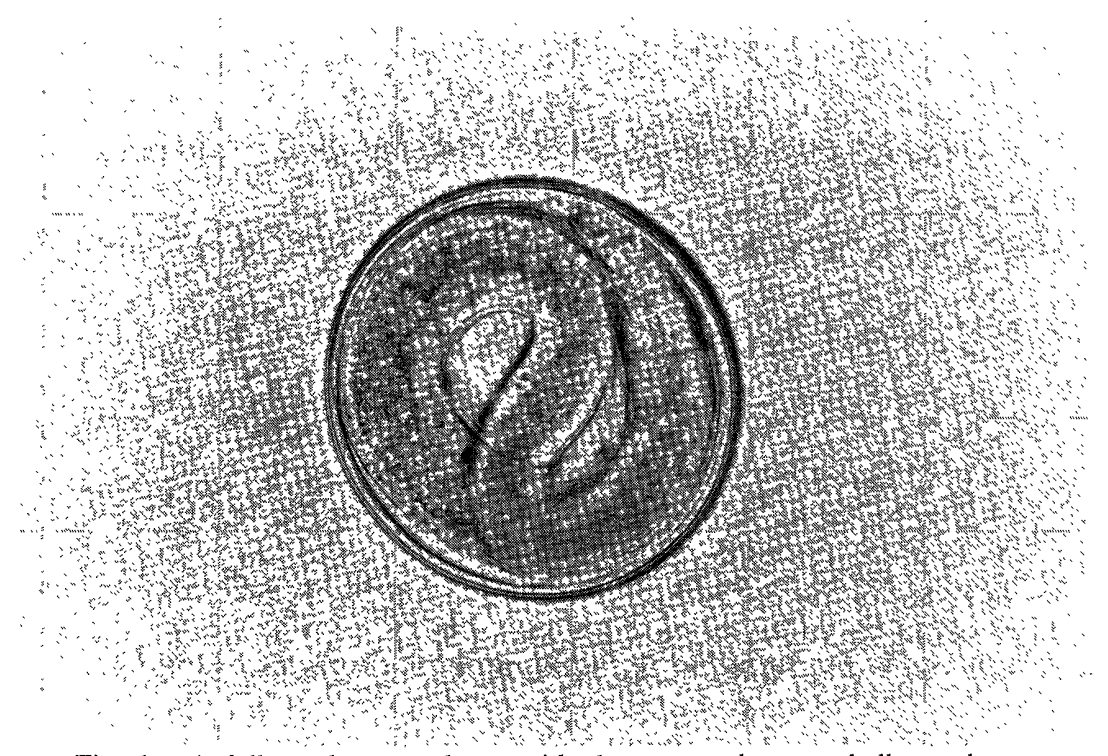

Fig. 1. A fully embryonated egg with the removed outer shell membrane.

were divided into 3 groups of 24,29 and 29 birds, respectively. Each quail of Group 1 was inoculated with $0.85 \mathrm{ml}$ of the suspension containing 4,000 eggs and the birds of Group 2 were each given $0.58 \mathrm{ml}$ of the suspension containing 15,000 eggs by the same method as in Trial-1. Group 3 consisting of 26 quails was used as uninoculated control.

Before inoculation, quails were fasted overnight. Both inoculated and control quails were kept separately in an air conditioned room with a mean temperature of $25^{\circ} \mathrm{C}$, a mean humidity of $60 \%$ and a photoperiod regime of $14 \mathrm{~L}: 10 \mathrm{D}$. Quails were fed with feed mash and water ad libitum.

Examination of pathological changes: The quails were killed between $12 \mathrm{hr}$ and 200 days post inoculation in Trial-1, and between $6 \mathrm{hr}$ and 52 days in Trial-2. At autopsy, gross pathological changes were recorded. In Trial-2, a half of the liver was submitted to pathological examination. The tissue was fixed in $10 \%$ formalin saline for 2 or 3 days and embedded in paraffin, and sections were stained with hematoxylin and eosin. The other half of the organ was used to recover ascarid larvae.

Counting the larvae in the organs: In Trial-1, the organs such as the liver, heart, muscle of breast and leg, gizzard, brain and eyes, and in Trial-2, the liver and breast and leg muscles were submitted to counting the larvae by a slightly modified method of Kondo's [8]. The larvae in the muscles of the breast and legs were separately examined 80, 100 and 200 days after inoculation. Each muscle and organ were cut into small pieces with a pair of scissors. A part of the cut specimen was digested in 9 parts of $0.1 \%$ pepsin solution $(0.1 \mathrm{~g}$ of pepsin, 1:10,000, DIFCO, was dissolved in $100 \mathrm{ml}$ of $0.7 \% \mathrm{HCl}$ solution), at $37^{\circ} \mathrm{C}$ for 3 to $8 \mathrm{hr}$. Then, the digested specimen was filtrated through a stainless steel sieve with $0.5 \mathrm{~mm}$ mesh. The filtrate was washed with saline by centrifugation at 3,000 to $4,000 \mathrm{rpm}$ for $5 \mathrm{~min}$. A small portion of the sediments was pressed between two slide glasses and observed under a low magnification of $\times 40$. All the larvae in organ and muscle specimens were counted. In the case of the liver in Trial-2, the count of larvae was doubled.

Oral Inoculation of $T$. canis larvae into a puppy: An about 50-day-old male puppy weighing $1.5 \mathrm{~kg}$ was used. From 18 to 16 days and 12 and 11 days prior to inoculation of the larvae, $50 \mathrm{mg}$ flubendasol (Flumoxal: Fujisawa) was given orally to the dog daily to eliminate ancylostomes. Before inoculation of larvae, the dog was confirmed to be free from the infection with intestinal helminths. The dog was given with chopped raw liver containing about 1,000 larvae derived from a quail inoculated with 30,000 $T$. canis eggs and killed 12 days after inoculation. The puppy was daily examined for ascarid eggs excreted in the feces and then was necropsied 35 days post inoculation.

\section{RESULTS}

Trial-1: The distribution and frequency of $T$. canis larvae in the organs of Japanese quails inoculated wiht 1,500 ascarid eggs are given in Table 1. Larvae 
Table 1. Distribution of $T$. canis larvae in the organs of Japanese quails inoculated with 1,500 eggs

\begin{tabular}{|c|c|c|c|c|c|c|c|}
\hline \multirow{2}{*}{$\begin{array}{l}\text { Days after } \\
\text { inoculation }\end{array}$} & \multirow{2}{*}{$\begin{array}{l}\text { Quail } \\
\text { No. }\end{array}$} & \multicolumn{6}{|c|}{ Number of larvae recovered from } \\
\hline & & Liver & Heart & Muscles $^{\text {b) }}$ & Gizzard & Brain & Eyes \\
\hline \multirow[t]{2}{*}{$1 / 2$} & 1 & 33 & 0 & $\mathrm{NE}^{\mathrm{c})}$ & 1 & 0 & $\mathrm{NE}$ \\
\hline & 2 & 268 & 0 & 0 & 1 & 1 & $\mathrm{NE}$ \\
\hline \multirow[t]{3}{*}{2} & $3^{\text {a) }}$ & 850 & 1 & $\mathrm{NE}$ & 3 & 0 & 0 \\
\hline & 4 & 86 & 0 & 2 & 1 & 1 & 0 \\
\hline & 5 & 53 & $\mathrm{NE}$ & 1 & $\mathrm{NE}$ & $\mathrm{NE}$ & $\mathrm{NE}$ \\
\hline \multirow[t]{2}{*}{3} & 6 & 131 & 3 & 4 & 0 & 8 & 0 \\
\hline & 7 & 33 & 1 & 0 & 0 & 0 & 0 \\
\hline \multirow[t]{2}{*}{6} & 8 & 68 & 2 & 3 & 0 & 5 & 0 \\
\hline & 9 & 78 & 8 & 3 & 0 & 1 & 0 \\
\hline \multirow[t]{2}{*}{10} & 10 & 112 & 1 & 2 & 0 & 0 & 0 \\
\hline & 11 & 126 & 3 & 0 & 0 & 0 & 0 \\
\hline \multirow[t]{2}{*}{20} & 12 & 78 & 0 & 0 & 0 & 1 & 0 \\
\hline & 13 & 180 & 1 & 2 & 0 & 5 & 0 \\
\hline \multirow[t]{2}{*}{30} & 14 & 62 & 1 & 1 & 0 & 0 & 0 \\
\hline & 15 & 101 & 1 & 5 & 0 & 2 & 0 \\
\hline \multirow[t]{2}{*}{40} & 16 & 292 & 2 & 3 & 0 & 6 & 0 \\
\hline & 17 & 344 & 0 & 2 & 0 & 1 & 0 \\
\hline \multirow[t]{2}{*}{60} & 18 & 174 & 6 & 8 & 1 & 10 & 0 \\
\hline & 19 & 80 & 1 & 4 & 0 & 6 & 0 \\
\hline \multirow[t]{2}{*}{80} & 20 & 207 & 3 & $0^{\mathrm{d})}$ & 2 & 6 & 0 \\
\hline & 21 & 122 & 0 & $6^{(\mathrm{d})}$ & 0 & 6 & 1 \\
\hline \multirow[t]{2}{*}{100} & 22 & 397 & 0 & $2^{(\mathrm{d})}$ & 0 & 0 & 1 \\
\hline & 23 & 107 & 0 & $1^{\mathrm{d})}$ & 0 & 9 & 0 \\
\hline \multirow[t]{2}{*}{120} & 24 & 7 & 0 & 0 & 0 & 0 & 0 \\
\hline & 25 & 18 & 0 & 1 & 0 & 0 & 0 \\
\hline \multirow[t]{2}{*}{200} & 26 & 37 & 0 & $0^{\mathrm{d})}$ & 0 & 0 & 0 \\
\hline & 27 & 94 & 0 & $0^{\mathrm{d})}$ & 0 & 2 & 0 \\
\hline
\end{tabular}

a) In quail No. 3, many small white foci were observed on the surface of the liver.

b) A mixture of the breast and leg muscles.

c) Not examined.

d) Larvae were detected in the breast muscles but not in the leg muscles.

migrated into the organs and muscles within a half or 2 days after oral administration. In the liver, larvae were found continuously from $12 \mathrm{hr}$ to 200 days after inoculation. In the other organs, larvae were detected intermittently during the experimental period. The number of larvae detected varied from 7 to 850 in the liver, 1 to 8 in the heart, 1 to 8 in the muscles, 1 to 3 in the gizzard, 1 to 10 in the brain, and 1 in the eyes. All the larvae found in each organ seemed to be in the third stage showing length of approximately $0.4 \mathrm{~mm}$. On days 80,100 and 200 post inoculation, larvae were detected only in the breast muscles, but not in the leg muscles. The larvae recovered from the liver 200 days after inoculation remained alive and moved actively under microscopic observation. In quail No. 3 killed on 2 days after inoculation, many small white foci were observed on the surface of the liver and 850 larvae were recovered from the organ. No gross pathological lesion was observed in the liver of the other infected birds. Although larvae were reco- vered from the brain and eyes, no neurologic symptom was observed in the birds.

Trial-2: In the quails inoculated with 4,000 eggs, larvae were found as early as $6 \mathrm{hr}$ post inoculation. In the liver, larvae were detected through the observation period of $6 \mathrm{hr}$ to 52 days after inoculation. In the breast and/or leg muscle, larvae were found in almost all the birds inoculated. The number of larvae varied from 10 to 914 in the liver, 1 to 16 in the breast muscles, and 1 to 16 in the leg muscles (Table 2).

In the quails inoculated with 15,000 eggs, the distribution of larvae in the liver and muscles was almost the same as in the birds inoculated with 4,000 eggs except for the number of larvae detected. The number of larvae varied from 22 to 3,346 in the liver, 1 to 127 in the breast muscles, 1 to 176 in the leg muscles. The number of the larvae recovered from the liver was greater than that from the other organs examined (Table 3 ).

Three of 6 birds inoculated with 15,000 eggs died 
Table 2. Distribution of $T$. canis larvae in the organs of Japanese quails inoculated with 4,000 eggs

\begin{tabular}{|c|c|c|c|c|c|}
\hline \multirow{2}{*}{$\begin{array}{l}\text { Days after } \\
\text { inoculation }\end{array}$} & \multirow{2}{*}{$\begin{array}{l}\text { Quail } \\
\text { No. }\end{array}$} & \multicolumn{4}{|c|}{ Number of larvae recovered from } \\
\hline & & Liver $^{\text {a) }}$ & Breast & Leg & Breast \& Leg \\
\hline \multirow[t]{3}{*}{$1 / 4$} & 1 & 10 & 0 & 5 & 5 \\
\hline & 2 & 50 & 0 & 0 & 0 \\
\hline & 3 & 0 & 1 & 0 & 1 \\
\hline \multirow[t]{3}{*}{$1 / 2$} & 4 & 106 & 0 & 0 & 0 \\
\hline & 5 & 16 & 1 & 0 & 1 \\
\hline & 6 & 38 & 0 & 0 & 0 \\
\hline \multirow[t]{3}{*}{1} & 7 & 106 & 0 & 1 & 1 \\
\hline & 8 & 262 & 0 & 7 & 7 \\
\hline & 9 & 22 & 0 & 0 & 0 \\
\hline \multirow[t]{3}{*}{3} & 10 & 330 & 9 & 9 & 18 \\
\hline & 11 & $+{ }^{b)}$ & 1 & 3 & 4 \\
\hline & 12 & 298 & 12 & 8 & 20 \\
\hline \multirow[t]{3}{*}{6} & 13 & 188 & 3 & 16 & 19 \\
\hline & 14 & 378 & 1 & 9 & 10 \\
\hline & 15 & 760 & 6 & 2 & 8 \\
\hline \multirow[t]{2}{*}{15} & 16 & $+{ }^{b)}$ & 2 & 0 & 2 \\
\hline & 17 & 338 & 3 & 1 & 4 \\
\hline \multirow[t]{2}{*}{30} & 18 & 250 & 16 & 3 & 19 \\
\hline & 19 & 312 & 4 & 2 & 6 \\
\hline \multirow[t]{3}{*}{51} & 20 & 148 & 0 & 2 & 2 \\
\hline & 21 & 222 & 5 & 2 & 7 \\
\hline & 22 & 914 & 1 & 1 & 2 \\
\hline \multirow[t]{2}{*}{52} & 23 & 168 & 3 & 4 & 7 \\
\hline & - 24 & 410 & 4 & 5 & 9 \\
\hline
\end{tabular}

a) The number is reckoned by doubling that of larvae recovered from a half of the liver.

b) Although no larvae were recovered from a half of the liver examined, larvae were detected in the pathological examination on the other half.

on day 6 after inoculation. A great number of white foci and hemorrhage were observed in the liver of these birds. The number of larvae in the dead birds varied from 1,946 to 3,346 in the liver, 29 to 114 in the breast muscles, 43 to 48 in the leg muscles.

Gross pathological changes in the liver such as small white foci varying in size from a pin head to $0.5 \mathrm{~mm}$ in diameter were observed from $12 \mathrm{hr}$ after inoculation. Several and almost all the birds in groups 1 and 2 had the gross lesions. The same lesions were also observed on the cut surface of liver of both groups (Tables 4, 5).

In histopathological examination, larvae in sinusoids and pathological changes such as small necrotic foci and slight leukocytic infiltrations were observed from $6 \mathrm{hr}$ after inoculation. The histopathological changes seemed to become more remarkable in the later stage of infection in groups 1 and 2 . In both groups inoculated with 4,000 and 15,000 eggs respectively, granulomatous inflammation appeared in the liver 3 days after inoculation. The granulomatous inflammation consisted of lymphocytes, acidophilic cells and macrophages (Fig. 2). Granulomatous nodules mainly consisting of lymphocytes were surrounded by thin fibrous connective tissue, and pseudohepatic ducts and thickening of blood vessel wall appeared from 30 days after inoculation (Fig. 3). Granulomatous inflammations and nodules attained to $0.5 \mathrm{~mm}$ in diameter. Around larvae, no pathological changes were observed. The histopathological changes in the liver were similar in both groups of quails inoculated with 4,000 and 15,000 eggs respectively, although the gross and histopathological changes of the liver were more remarkable in the quails inoculated with 15,000 eggs than those in the birds with 4,000 eggs (Tables 4, 5). On the other hand, no pathological change was observed in the liver and the other organs in the uninoculated control groups.

In quail Nos. 17, 19, 21, 22 and 24 inoculated with 4,000 eggs and Nos. 23, 24, 26, 27, 28 and 29 inoculated with 15,000 eggs, gross pathological changes were also observed in the pancreas, heart and duodenum. From the pancreas, 2 to 84 larvae were recovered.

Oral inoculation of $T$. canis larvae into a puppy: In order to confirm that the quail serves as paratenic host for $T$. canis, 1,000 larvae harvested from the 
Table 3. Distribution of $T$. canis larvae in the organs of Japanese quails inoculated with 15,000 eggs

\begin{tabular}{|c|c|c|c|c|c|}
\hline \multirow{2}{*}{$\begin{array}{l}\text { Days after } \\
\text { inoculation }\end{array}$} & \multirow{2}{*}{$\begin{array}{l}\text { Quail } \\
\text { No. }\end{array}$} & \multicolumn{4}{|c|}{ Number of larvae recovered from } \\
\hline & & Liver $^{\mathrm{a})}$ & Breast & Leg & Breast \& Leg \\
\hline \multirow[t]{3}{*}{$1 / 4$} & 1 & 22 & 2 & 0 & 2 \\
\hline & 2 & 22 & 1 & 0 & 1 \\
\hline & 3 & 30 & 0 & 0 & 0 \\
\hline \multirow[t]{3}{*}{$1 / 2$} & 4 & 1,654 & 0 & $\mathrm{NE}^{\mathrm{b})}$ & $\mathrm{NE}$ \\
\hline & 5 & 1,230 & 0 & 1 & 1 \\
\hline & 6 & 660 & 0 & 0 & 0 \\
\hline \multirow[t]{3}{*}{1} & 7 & 490 & 41 & 22 & 63 \\
\hline & 8 & 1,110 & 26 & 17 & 43 \\
\hline & 9 & 650 & 0 & 6 & 6 \\
\hline \multirow[t]{4}{*}{3} & 10 & 398 & 11 & 10 & 21 \\
\hline & 11 & 1,526 & $\mathrm{NE}$ & $\mathrm{NE}$ & $\mathrm{NE}$ \\
\hline & 12 & 446 & 19 & 31 & 50 \\
\hline & 13 & 1,858 & 99 & 176 & 275 \\
\hline \multirow[t]{6}{*}{6} & 14 & 762 & 20 & 25 & 45 \\
\hline & 15 & 2,784 & 127 & 161 & 288 \\
\hline & 16 & 848 & 17 & 20 & 37 \\
\hline & $17^{\mathrm{c})}$ & 3,346 & 29 & 48 & 77 \\
\hline & $18^{c)}$ & 1,946 & 41 & 43 & 84 \\
\hline & $19^{c)}$ & 2,478 & 114 & 48 & 162 \\
\hline \multirow[t]{3}{*}{15} & 20 & 1,736 & 82 & 47 & 129 \\
\hline & 21 & 1,386 & 19 & 8 & 27 \\
\hline & 22 & 942 & $\mathrm{NE}$ & 16 & 16 \\
\hline \multirow[t]{3}{*}{30} & 23 & 1,898 & 65 & 10 & 75 \\
\hline & 24 & 1,088 & 54 & 8 & 62 \\
\hline & 25 & 1,180 & 1 & 2 & 3 \\
\hline \multirow[t]{3}{*}{51} & 26 & 1,514 & 3 & 3 & 6 \\
\hline & 27 & 700 & $\mathrm{NE}$ & $\mathrm{NE}$ & $\mathrm{NE}$ \\
\hline & 28 & 1,848 & $\mathrm{NE}$ & $\mathrm{NE}$ & $\mathrm{NE}$ \\
\hline 52 & 29 & 2,270 & 55 & 19 & 74 \\
\hline
\end{tabular}

a) The number is reckoned by doubling that of larvae recovered from a half of the liver.

b) Not examined.

c) Three quails died 6 days after inoculation.

liver of an infected bird were orally given to a puppy. The puppy began to excrete $T$. canis eggs from 33 days after inoculation. On day 35 after inoculation, the puppy was autopsied. Although no significant gross pathological changes were observed in all the organs, 77 mature and immature worms of $T$. canis parasitized the dog in the upper part of the small intestine. The worms varied in the length from 1.1 to $7.5 \mathrm{~cm}$.

\section{DISCUSSION}

In the present experiments, it was proved that Japanese quails, Coturnix coturnix japonica, serve as a paratenic host for Toxocara canis. In this case, prepatent period was 33 days. $T$. canis eggs given to quails hatched in a short term and the larvae invaded the liver and muscle within $6 \mathrm{hr}$ after inoculation. Furthermore, the larvae invaded and persisted in the heart, gizzard and other organs for a relatively long period.

Although larvae were also recovered from the breast and leg muscles, brain, eyes and gizzard, most of them were detected from the liver regardless of inoculum sizes, just as in the experiments with chickens $[10,12]$. In the quail, most larvae were detected in the liver and remained alive and active there even 200 days after inoculation. In the monkey, the larvae persisted in the liver for 7 years [2]. These results indicate that the liver is the most favorable site for ascarid larvae.

In Trial-2, one of the major purposes is the observation of macroscopical changes in the liver. In this Trial, gross pathological as well as histopathological changes in quail liver tended to become more serious with the larger number of $T$. canis eggs inoculated, and with the progress of infection. In the experiments, only male birds were used so as not to make the observation difficult by accumulation of triglycerides, phospholipid and lipoprotein in laying 
Table 4. Pathological changes in the liver of Japanese quails inoculated with 4,000 eggs

\begin{tabular}{|c|c|c|c|c|c|c|c|}
\hline \multirow{2}{*}{$\begin{array}{l}\text { Days after } \\
\text { inoculation }\end{array}$} & \multirow{2}{*}{$\begin{array}{l}\text { Quail } \\
\text { No. }\end{array}$} & \multicolumn{2}{|c|}{$\begin{array}{l}\text { Degree of patho- } \\
\text { logical changes }\end{array}$} & \multicolumn{4}{|c|}{ Histopathological changes } \\
\hline & & Gross $^{\text {a) }}$ & Histological $^{\mathrm{b})}$ & $\mathrm{Nec}^{\mathrm{c})}$ & $\mathrm{Aci}^{\mathrm{c})}$ & $\mathrm{Gra}^{\mathrm{c})}$ & Nod $^{\text {c) }}$ \\
\hline \multirow[t]{3}{*}{$1 / 4$} & 1 & - & - & - & - & - & - \\
\hline & 2 & - & + & 0 & 0 & - & - \\
\hline & 3 & - & - & - & - & - & - \\
\hline \multirow[t]{3}{*}{$1 / 2$} & 4 & + & + & 0 & 0 & - & - \\
\hline & 5 & - & + & 0 & 0 & - & - \\
\hline & 6 & + & H & 0 & 0 & - & - \\
\hline \multirow[t]{3}{*}{1} & 7 & + & $H$ & 0 & 0 & - & - \\
\hline & 8 & + & + & 0 & 0 & - & - \\
\hline & 9 & + & H & 0 & 0 & - & - \\
\hline \multirow[t]{3}{*}{3} & 10 & + & H & 0 & 0 & - & - \\
\hline & 11 & - & H & 0 & 0 & 0 & - \\
\hline & 12 & + & H & 0 & $\mathrm{O}$ & 0 & - \\
\hline \multirow[t]{3}{*}{6} & 13 & - & $\mathrm{HH}$ & 0 & - & 0 & - \\
\hline & 14 & H & m+ & 0 & 0 & 0 & - \\
\hline & 15 & - & $H$ & 0 & 0 & 0 & - \\
\hline \multirow[t]{2}{*}{15} & 16 & - & H & 0 & 0 & 0 & - \\
\hline & 17 & - & H & 0 & 0 & 0 & - \\
\hline \multirow[t]{2}{*}{30} & 18 & - & + & 0 & 0 & - & - \\
\hline & 19 & - & m & 0 & 0 & 0 & 0 \\
\hline \multirow[t]{3}{*}{51} & 20 & - & H & 0 & 0 & 0 & 0 \\
\hline & 21 & + & H & 0 & 0 & 0 & - \\
\hline & 22 & - & H & 0 & 0 & 0 & 0 \\
\hline \multirow[t]{2}{*}{52} & 23 & - & H & 0 & 0 & 0 & 0 \\
\hline & 24 & + & H & 0 & 0 & 0 & 0 \\
\hline
\end{tabular}

a) White foci observed in the cortex are classified into three grades of frequency from + to $\mathrm{Ht}$. $-:$ negative, $+:<10,+: 10 \sim 30, \mathrm{~m}: 30<$.

b) Histopathological changes are classified into three grades of degree from + to $\mathrm{W}$. -: negative, +: weak, + : moderate, $\mathrm{H}$ : remarkable.

c) Nec: necrosis, Aci: infiltration of acidophilic cells, Gra: granulomatous inflammation, Nod: formation of granulomatous nodules, - : negative, $\mathrm{O}$ : positive.

birds. Since the pathological changes in the liver of the Japanese quail were similar to those in chickens, quails can be used as an animal model for $T$. canis infection in chickens with some advantages such as the small size of body, which facilitates the handling of animals in a long term experiment and examination of whole visceral organs and muscles for parasites.

Ascarid larvae have been recovered from the muscle and viscera of domestic animals such as pigs, sheep and chickens experimentally infected with $T$. canis $[4,10-12]$. This suggests that the raw or insufficiently cooked meats and viscera of the infected animals including Japanese quails can be the sources of VLM. In fact, Ito et al. [7] reported two human clinical cases of VLM with $T$. canis due to the ingestion of raw chicken and cattle liver.

Okoshi et al. [10] reported that earth worms could be infected with $T$. canis eggs and chickens were infected with the larvae by ingesting infected earthworms. Domestic fowls such as chickens and quails have a behavior to pick up earthworms with feed in the field. Furthermore, raw meat, liver, gizzard and heart of chicken, pheasant and quail are often consumed in some areas of Japan. Due to the reasons mentioned above, the chickens, so-called "Zidori", or quails freely ranged in a farm contaminated with $T$. canis eggs may serve as one of infective sources of VLM.

ACKNOWLEDGEMENTS. A part of the study was suported by a grant of Ministry of Health and Welfare.

\section{REFERENCES}

1. Beaver, P. C., Snyder, C. H., Carrera, G. M., Dent, J. H., and Lafferty, J. W. 1952. Chronic eosinophilia due to visceral larva migrans. Report of three cases. Pediatrics 9: 7-19.

2. Beaver, P. C. 1962. Toxocariais (visceral larva migrans) in relation to tropical eosinophilia. Bull. Soc. Pathol. Exot. 55: 555-576.

3. Beaver, P. C. 1969. The nature of visceral larva migrans. $J$. Parasitol. 55: 3-12.

4. Done, J. T., Richardson, M. D., and Gibson, T. E. 1960. Experimental visceral larva migrans in the pig. Res. Vet. Sci. 
Table 5. Pathological changes in the liver of Japanese quails inoculated with 15,000 eggs

\begin{tabular}{|c|c|c|c|c|c|c|c|}
\hline \multirow{2}{*}{$\begin{array}{l}\text { Days after } \\
\text { inoculation }\end{array}$} & \multirow{2}{*}{$\begin{array}{l}\text { Quail } \\
\text { No. }\end{array}$} & \multicolumn{2}{|c|}{$\begin{array}{l}\text { Degree of patho- } \\
\text { logical changes }\end{array}$} & \multicolumn{4}{|c|}{ Histopathological changes } \\
\hline & & Gross $^{\text {a) }}$ & Histological $^{\mathrm{b})}$ & $\mathrm{Nec}^{\mathrm{c})}$ & $\mathrm{Aci}^{\mathrm{c})}$ & $\left(\mathrm{Gra}^{\mathrm{c})}\right.$ & Nod $^{\text {c) }}$ \\
\hline \multirow[t]{3}{*}{$1 / 4$} & 1 & - & - & - & - & - & - \\
\hline & 2 & - & $\mathrm{HH}$ & 0 & 0 & - & - \\
\hline & 3 & - & + & - & 0 & - & - \\
\hline \multirow{3}{*}{$1 / 2$} & 4 & H & H+ & 0 & 0 & - & - \\
\hline & 5 & H & H & 0 & 0 & - & - \\
\hline & 6 & $\mathrm{H}$ & \# & 0 & $\mathrm{O}$ & - & - \\
\hline \multirow[t]{3}{*}{1} & 7 & + & \# & 0 & 0 & - & - \\
\hline & 8 & + & H & 0 & 0 & - & - \\
\hline & 9 & H & m & 0 & 0 & - & - \\
\hline \multirow[t]{4}{*}{3} & 10 & m & m & 0 & 0 & - & - \\
\hline & 11 & + & m & 0. & 0 & - & - \\
\hline & 12 & m+ & m & 0 & 0 & - & - \\
\hline & 13 & - & m & 0 & 0 & 0 & - \\
\hline \multirow[t]{6}{*}{6} & 14 & + & m & 0 & 0 & 0 & - \\
\hline & 15 & m & H & 0 & 0 & 0 & - \\
\hline & 16 & H & m & 0 & 0 & - & - \\
\hline & $17^{\mathrm{d})}$ & $+\mathrm{H}(\mathrm{H})^{\mathrm{e})}$ & H & 0 & 0 & 0 & - \\
\hline & $18^{\mathrm{d})}$ & $+H(H)$ & \#+ $(\mathrm{H})$ & 0 & 0 & - & - \\
\hline & $19^{\mathrm{d})}$ & $H(\mathrm{H})$ & \# $(\mathrm{H})$ & 0 & 0 & - & - \\
\hline \multirow[t]{3}{*}{15} & 20 & + & H & 0 & 0 & 0 & - \\
\hline & 21 & m & m & 0 & 0 & 0 & - \\
\hline & 22 & H & H & 0 & 0 & 0 & - \\
\hline \multirow[t]{3}{*}{30} & 23 & m & m & 0 & 0 & 0 & - \\
\hline & 24 & + & m & 0 & 0 & 0 & 0 \\
\hline & 25 & m & m & 0 & 0 & 0 & 0 \\
\hline \multirow[t]{3}{*}{51} & 26 & m & $\mathrm{H}$ & 0 & 0 & 0 & 0 \\
\hline & 27 & m & m & 0 & 0 & 0 & 0 \\
\hline & 28 & m & m & 0 & 0 & 0 & 0 \\
\hline 52 & 29 & m & m & 0 & 0 & 0 & 0 \\
\hline
\end{tabular}

a) White foci observed in the cortex are classified into three grades of frequency from + to $\mathrm{H}$. $-:$ negative, $+:<10,+$ : $10 \sim 30, \mathrm{~m}: 30<$.

b) Histopathological changes are classified into three grades of degree from + to $\mathrm{W}$. -: negative, +: weak, H: moderate, m: remarkable.

c) Nec: necrosis, Aci: infiltration of acidophilic cells, Gra: granulomatous inflammation, Nod: formation of granulomatous nodules, - : negative, $\bigcirc$ : positive.

d) Three quails died 6 days after inoculation.

e) $\mathrm{H}$ : hemorrhage.

1: $133-151$.

5. Ehrhard, T. and Kernbaum, S. 1979. Toxocara canis et toxocarose humaine. Bull. Inst. Pasteur 77: 225-227.

6. Glickman, L. T. and Schaantz, P. M. 1981. Epidemiology and pathogenesis of zoonotic toxocariasis. Epidemiol. Rev. 3: $230-250$.

7. Ito, K., Sakai, K., Okajima, T., Ouchi, K., Funakoshi, A., Nishimura, J., Ibayashi, H., and Tsuji, M. 1986. Three cases of visceral larva migrans due to ingestion of raw chicken or cow liver. J. Jpn. Soc. Intern. Med. 75: 759-766 (in Japanese).

8. Kondo, K. 1970. Experimental studies on "Larva migrans".
J. Kyoto Pref. Univ. Med. 79: 32-56 (in Japanese).

9. Kondo, K. 1986. Human infection with animal ascaridae. Infection of Ascarididae derived from animal in man. J. Vet. Med. No. 782: 26-30 (in Japanese).

10. Okoshi, S. and Usui, M. 1968. Experimental studies on Toxascaris leonina. VI. Experimental infection of mice, chickens, and earthworms with Toxascaris leonina, Toxocara canis, and Toxocara cati. Jpn. J. Vet. Sci. 30: 151-166.

11. Shaeffler, W. F. 1960. Experimental infection of sheep with the dog ascarid, Toxocara canis. J. Parasitol. 46 (Suppl): 17.

12. Thomas, J. G. 1964. Experimental Toxocara canis infection in chickens and pigeons. J. Parasitol. 50: 124-127. 


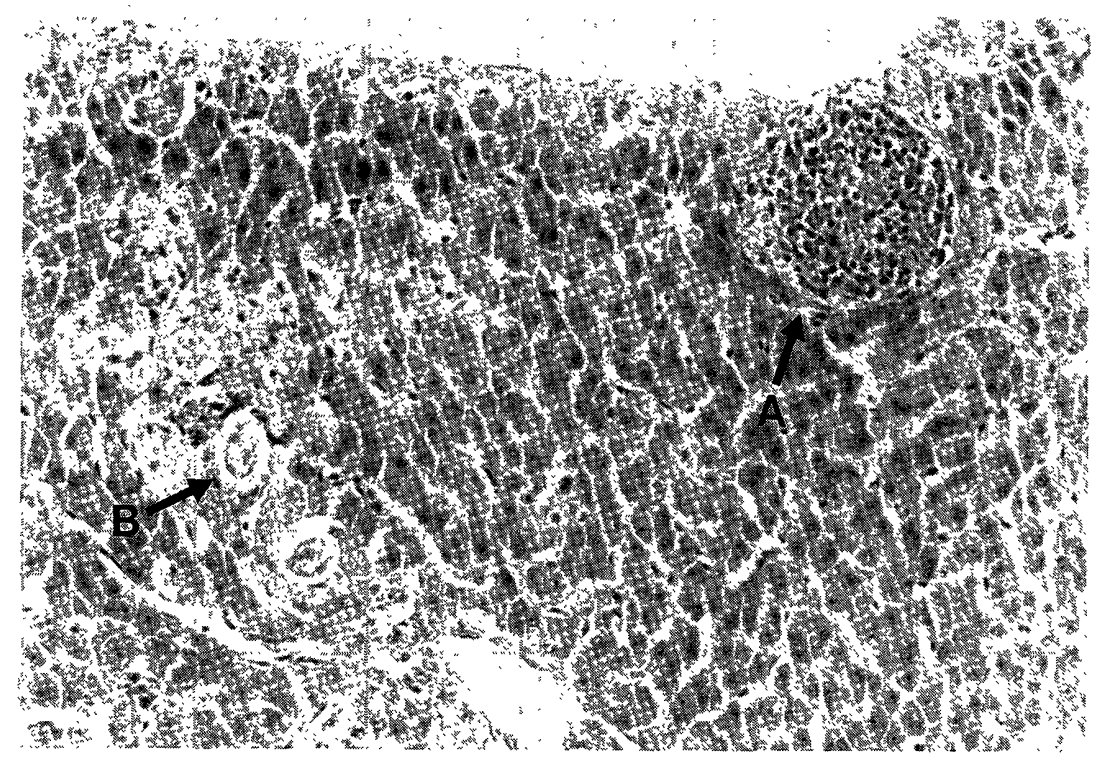

Fig. 2. The lesion in the liver of quail No. 15, 6 days after inoculation of 4,000 eggs. The granulomatous inflammation consists of lymphocytes, acidophilic cells and macrophages (arrow A), and T. canis larvae (arrow B) are seen.

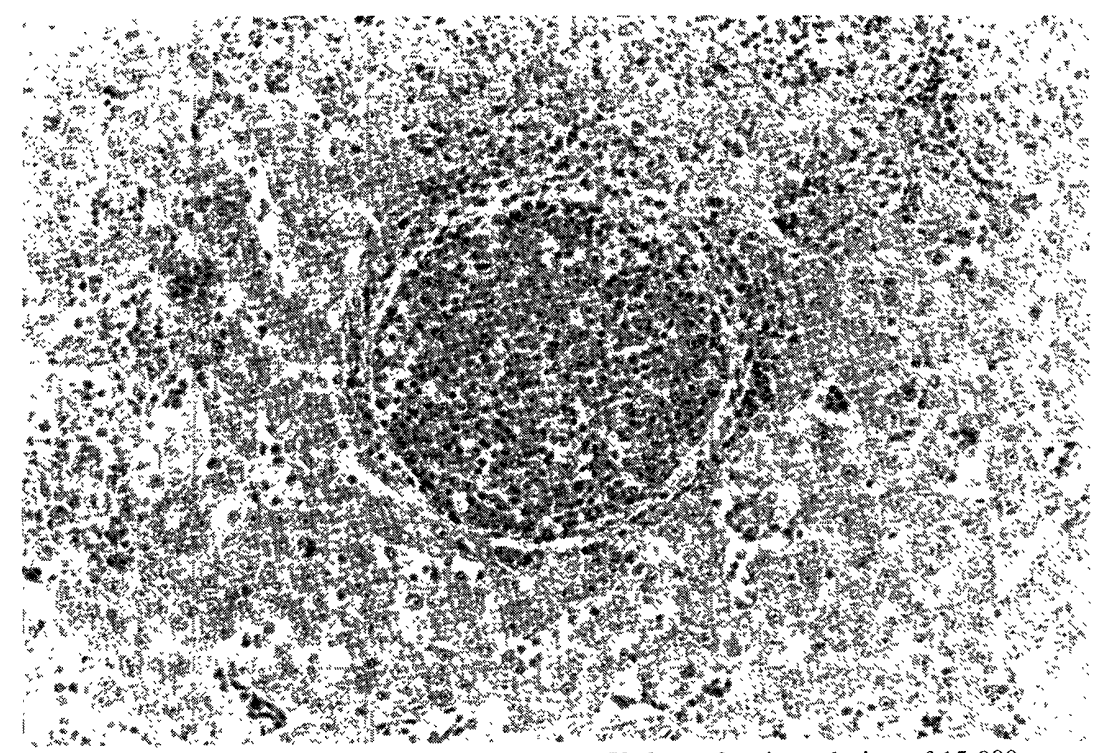

Fig. 3. The lesion in the liver of quail No. 29, 52 days after inoculation of 15,000 eggs. Granulomatous nodule mainly consisting of lymphocytes and surrounded by thin fibrous connective tissue is seen. 